\title{
The Ameliorating Effects of Bee Pollen on Scopolamine-Induced Cognitive Impairment in Mice
}

\author{
Yulan Liao, ${ }^{a}$ Ho Jung Bae, ${ }^{a}$ Jiabao Zhang, ${ }^{a}$ Yubeen Kwon, ${ }^{a}$ Bokyung Koo, ${ }^{a}$ In Ho Jung, ${ }^{a}$ \\ Hye Min Kim, ${ }^{b}$ Jong Hun Park, ${ }^{c}$ Jae Hwan Lew, ${ }^{c}$ and Jong Hoon Ryu ${ }^{* a, d}$ \\ ${ }^{a}$ Department of Life and Nanopharmaceutical Science, Kyung Hee University; Seoul 02447, Republic of Korea: \\ ${ }^{b}$ Daehwa Pharmaceutical Co., Ltd.; Seongnam 13488, Gyeonggi-do, Republic of Korea: ${ }^{c}$ Graduate School of \\ East-West Medical Science, Kyung Hee University; Yongin 17104, Republic of Korea: and ${ }^{d}$ Department of Oriental \\ Pharmaceutical Science, Kyung Hee University; Seoul 02447, Republic of Korea. \\ Received July 19, 2018; accepted December 2, 2018
}

\begin{abstract}
Bee pollen consists of floral pollen mixed with bee secretions and nectar. It has been considered as a functional food and has different kinds of biologically active ingredients, such as flavonoids, polyphenols, phytosterols and minerals. However, its function in cognition has yet been investigated. In the present study, we investigated the ameliorating effect of bee pollen against scopolamine-caused cognitive impairment through the passive avoidance test, the Y-maze test and the Morris water maze test. In addition, Western blotting was employed to verify the effects of bee pollen on memory-related signaling molecules in the hippocampus. Bee pollen extract $(100$ or $300 \mathrm{mg} / \mathrm{kg}$, per os $($ p.o. $)$ ) obviously reversed scopolamine-caused cognitive impairment in the passive avoidance test, ameliorated spontaneous alternation versus the scopolaminetreated group in the Y-maze test and prolonged swimming time in the target zone in the Morris water maze test. In addition, the phosphorylation levels of extracellular signal-regulated kinase (ERK), cAMP response

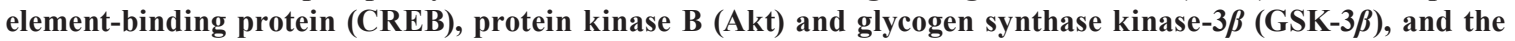
expression levels of brain-derived neurotrophic factor (BDNF) and tissue plasminogen activator (tPA) in the hippocampi, were increased in response to the treatment with bee pollen extract $(100$ or $300 \mathrm{mg} / \mathrm{kg}$, p.o.). These results indicated that bee pollen ameliorates cognitive impairment induced by cholinergic blockade through the enhancing conversion of proBDNF to mature BDNF by tPA, probably, through the ERK-CREB pathway or Akt-GSK-3 $\beta$ signaling pathway and would be a useful agent for the treatment of cognitive dysfunction.
\end{abstract}

Key words bee pollen; cognitive function; glycogen synthase kinase $3 \beta$; extracellular signal-regulated kinase; cAMP response element-binding protein; brain-derived neurotrophic factor

\section{INTRODUCTION}

Dementia is one of the most serious health issues around the world, and the most common form of dementia is Alzheimer's disease (AD) ${ }^{1,2)} \mathrm{AD}$ is a progressive neurodegenerative disease characterized by impairment of cognitive function. ${ }^{3)}$ The pathophysiological features of AD include synaptic and neuronal loss, ${ }^{4)}$ neuroinflammation, ${ }^{5)}$ neurotransmitter disturbances, ${ }^{6)}$ extracellular $\beta$-amyloid plaques ${ }^{7)}$ and intracellular hyperphosphorylated tau protein. ${ }^{8)}$ Currently, the therapy for $\mathrm{AD}$ is focused on stimulating the cholinergic neurotransmitter system, and thus, acetylcholinesterase (AChE) inhibitors, like donepezil, rivastigmine or galantamine, have been widely applied for the treatment of AD.,10) However, such agents have many adverse effects, including vomiting, insomnia, nausea, muscles cramps and loss of appetite. ${ }^{11,12)}$ Therefore, more effective therapeutic agents with fewer side effects are expected.

Bee pollen consists of floral pollen mixed with bee secretions and nectar. ${ }^{13)}$ It was used for skin whitening and for cosmetic purposes in ancient China, Egypt and Greece. ${ }^{14)}$ Recently, bee pollen as a functional food has gained a great deal of attentions due to its high content of biologically active components, such as vitamins, essential amino acids, flavonoids, polyphenols, phytosterols and minerals. ${ }^{15)}$ In addition, it has been reported that bee pollen has a large scope of therapeutic characters, like antimicrobial, antifungal, antioxi- dant, anti-radiation, hepatoprotective or anti-inflammatory activities. ${ }^{16-19)}$ Recently, it has also been reported that bee pollen could ameliorate glutamate excitotoxicity ${ }^{20)}$ and attenuate both brain strokes and heart disease, ${ }^{21)}$ suggesting that bee pollen might be a useful agent in the treatment of neurodegenerative disease. However, to our knowledge, there have not been any works published regarding the effect of bee pollen on cognitive functions.

In the present study, we investigated whether bee pollen exerts ameliorating effects on cognitive impairment caused by scopolamine, a nonselective muscarinic receptor antagonist, using the passive avoidance test, the Y-maze test and the Morris water test. In addition, Western blotting was selected to identify the effects of bee pollen on memory-related signaling molecules in the hippocampi.

\section{MATERIALS AND METHODS}

Animals We bought the 6-week-old male CD-1 mice (26-30 g) from the Orient Co., Ltd., a filiale of Charles River Laboratories (Seoul, Korea). Five mice were fed in each cage, and free accessed water and fodder. Mice were placed in a room for $7 \mathrm{~d}$ before all experiments. The conditions for keeping the mice are as follows: temperature $\left(23 \pm 1^{\circ} \mathrm{C}\right)$, humidity $(60 \pm 10 \%)$, a $12 \mathrm{~h}$ illumination/dark cycle (illumination time 7:00-19:00). All experimental protocols regarding the use of 
mice were approved by the Institutional Animal Care and Usage Committee of Kyung Hee University [approval No. KHUASP (SE)-16-131 (01/11/2017)]. Animal treatment and care were carried out according to the Animal Care and Use Guidelines issued by Kyung Hee University, Korea.

Materials We bought the donepezil hydrochloride, scopolamine hydrobromide and piracetam from Sigma-Aldrich Co. (St. Louis, MO, U.S.A.). We bought the protein kinase B (Akt), phosphorylated Akt, glycogen synthase kinase $3 \beta$ (GSK-3 $\beta$ ), extracellular signal-regulated kinase (ERK), cAMP response element-binding protein (CREB) and $\beta$-actin antibodies from Santa Cruz Biotechnology, Inc. (Santa Cruz, CA, U.S.A.). We bought the phosphorylated CREB, phosphorylated ERK and phosphorylated GSK- $3 \beta$ antibodies from Cell Signaling Technology, Inc. (Danvers, MA, U.S.A.). We bought the brain-derived neurotrophic factor (BDNF) from Abcam (Cambridge, U.K.). We bought the anti-rabbit, anti-mouse and anti-goat immunoglobulin $\mathrm{G}(\mathrm{IgG})$ antibodies from GeneTex, Inc. (Irvine, CA, U.S.A.). For RNA extraction and RT-PCR, Trizol reagent was obtained from Thermo Fisher Scientific (Waltham, MA, U.S.A.) and SYBR Premix Ex Taq was bought from TaKaRa Bio Inc. (Tokyo, Japan). Other materials were from general commercial resources and were the highest grades. Donepezil, piracetam and scopolamine were dissolved in $0.9 \%$ saline solution. Bee pollen extract was dissolved in 10\% Tween 80 solution.

Preparation of Bee Pollen Extract The bee pollen was purchased from BWB ${ }^{\circledR}$ Co. (Gyeonggi-do, Korea) who handled the bee pollen that originated from coffee flowers in Vietnam (made by Bee Nature Company, Ltd., Vietnam). The bee pollen $(50 \mathrm{~g})$ was extracted with $70 \%$ ethanol $(500 \mathrm{~mL})$ at $60^{\circ} \mathrm{C}$ for $2 \mathrm{~h}$ two times. The extracts were combined and filtered under a vacuum. Then, the extracts were concentrated at $40^{\circ} \mathrm{C}$ in vacuo and were freeze-dried under reduced pressure. The final bee pollen extract (yield; 43.4\%) was standardized based on three indication compounds (quercetin, luteolin and apigenin) to ensure the quality using the Agilent 1290 Infinity II LC Liquid Chromatography System (Agilent Technology, U.S.A.). The mean levels of luteolin, quercetin and apigenin in the bee pollen extract were $12.6 \pm 0.2,39.7 \pm 0.2$ and $29.8 \pm 0.1 \mathrm{mg} / \mathrm{kg}$, respectively (Fig. 1). The final product was kept in a desiccator at room temperature and with very low humidity $(20 \% \mathrm{RH}>)$.

Passive Avoidance Test (PAT) This test consisted of $2 \mathrm{~d}$ that the first day is an acquisition tentative and the second day is a retention tentative. Two same dimensional chambers $(20 \times 20 \times 20 \mathrm{~cm})$, which were isolated by a door $(5 \times 5 \mathrm{~cm})$, were used to carry out the test, as described elsewhere. ${ }^{22)}$ One of the chambers was a white chamber with a bulb $(50 \mathrm{~W})$, and another one was a black chamber without light. The floors of two chambers were made up by $2-\mathrm{mm}$ nonrust steel tubes, spaced 1-cm apart. On the first day, the bee pollen extract (30, 100 or $300 \mathrm{mg} / \mathrm{kg}$, per os (p.o.)) or donepezil $(5 \mathrm{mg} / \mathrm{kg}$, p.o.) was given to the mice $1 \mathrm{~h}$ before an acquisition tentative. The control group treated with the equal volume of $10 \%$ Tween 80 solution rather than bee pollen extract or donepezil. The animals were also given scopolamine $(1 \mathrm{mg} / \mathrm{kg}$, intraperitoneally (i.p.)) or $0.9 \%$ saline solution $30 \mathrm{~min}$ before the acquisition tentative. During the acquisition tentative, the mice were put in the white chamber, and after $10 \mathrm{~s}$ the door was opened. When the mice got into the black chamber, the door was closed,
A

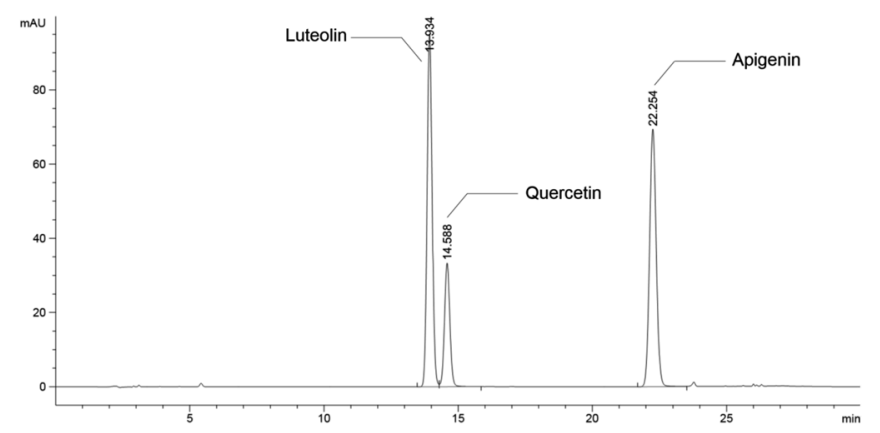

B

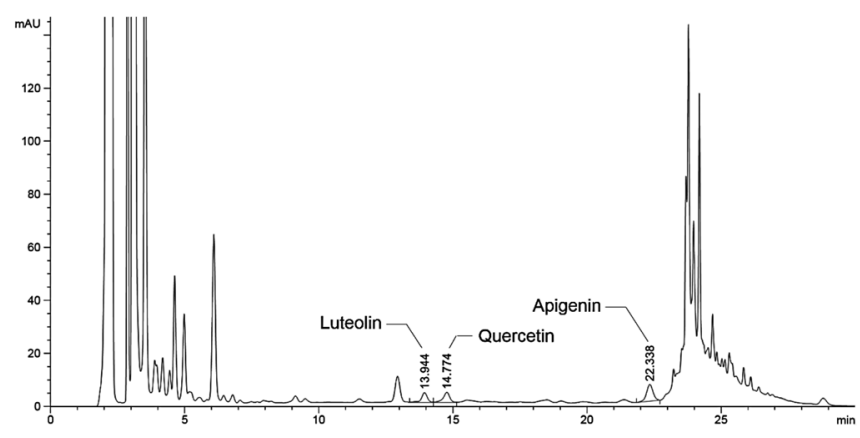

Fig. 1. Representative HPLC Chromatograms of Standard Compounds or of Bee Pollen Extract

The HPLC chromatograms of luteolin, quercetin and apigenin are presented (A). The HPLC profiles of luteolin, quercetin or apigenin from the bee pollen extract are presented (B). The conditions of HPLC were as follows: the ZORBAX Eclipse XDB column C18 $(250 \times 4.6 \mathrm{~mm}, 5 \mu \mathrm{m}$, Agilent technology); the mobile phase, comprised of $0.1 \%$ formic acid in distilled water (solvent $\mathrm{A}$ ) and acetonitrile (solvent $\mathrm{B}$ ), and the flow rate was $1 \mathrm{~mL} / \mathrm{min}$. The obtained elution conditions were as follows: $0-20 \mathrm{~min}$, a linear gradient from 75 to $70 \%$ of solvent $\mathrm{A} ; 20-25 \mathrm{~min}$, from 70 to $30 \%$ of solvent A; $25-30 \mathrm{~min}$, a linear gradient from 30 to $75 \%$ of solvent A. The detection was carried out at $356 \mathrm{~nm}$ and the injection volume was $10 \mu \mathrm{L}$. Luteolin, quercetin and apigenin were typically detected near $14,14.6$ and $22.3 \mathrm{~min}$, respectively. The concentrations of luteolin, quercetin and apigenin in the bee pollen extract were $12.6 \pm 0.2,39.7 \pm 0.2$ and $29.8 \pm 0.1 \mathrm{mg} / \mathrm{kg}$, respectively.

and an electro-shock $(3 \mathrm{~s}, 0.5 \mathrm{~mA})$ was conducted through the nonrust steel tubes to the mice. The retention tentative was carried out $24 \mathrm{~h}$ later. The mice were put in the white chamber again, and after $10 \mathrm{~s}$ the door was opened, just as in the acquisition tentative. If the mice got into the black chamber, they were not given the electro-shock. The time required for the mice gone into the black chamber after the door opening was used as the latency in both tentative. The maximum latency time was set up to $300 \mathrm{~s}$. If the mice did not get into the black chamber within $300 \mathrm{~s}$ after the door was opened, the latency was recorded as $300 \mathrm{~s}$.

For the cognitive enhancement study, the mice were given bee pollen extract $(30,100$ or $300 \mathrm{mg} / \mathrm{kg}$, p.o.) or piracetam $(200 \mathrm{mg} / \mathrm{kg}$, i.p.), as a positive control, $1 \mathrm{~h}$ before an acquisition tentative, as described elsewhere. ${ }^{23)}$ The control group treated with the equal volume of $10 \%$ Tween 80 solution rather than bee pollen extract or piracetam. When the mice got into the black chamber, the door was closed, and an electro-shock $(3 \mathrm{~s}$, $0.25 \mathrm{~mA}$ ) was conducted through the nonrust steel tubes to the mice. The retention tentative was conducted $24 \mathrm{~h}$ later. The latency time was set up to $600 \mathrm{~s}$. If the mice did not get into the black chamber within $600 \mathrm{~s}$ after the door was opened, the latency was recorded as $600 \mathrm{~s}$. The other procedures were as same as described above.

Y-Maze Test (Y-M) The test was conducted in a maze 
with 3 arms in which the arms were presented at $120^{\circ}$ angles to each other, as described previously. ${ }^{24)}$ The length, width and height of each arm were 40,3 and $12 \mathrm{~cm}$. The floor and walls of the Y-maze were constructed of black plastic. Bee pollen extract $(30,100$ or $300 \mathrm{mg} / \mathrm{kg}$, p.o.) or donepezil $(5 \mathrm{mg} / \mathrm{kg}$, p.o.) was given to the mice $1 \mathrm{~h}$ before the test. The control group was given the equal volume of $10 \%$ Tween 80 solution rather than bee pollen extract or donepezil. The mice were also given scopolamine $(1 \mathrm{mg} / \mathrm{kg}$, i.p.) or $0.9 \%$ saline solution (i.p.) $30 \mathrm{~min}$ before the test. During an 8 -min period, each mouse was randomly put in the maze, and using a video camera-installed Ethovision system (Nodulus, Wageningen, the Netherlands) to record all behaviors. The numbers of arm entries and sequence were analyzed by manual analysis. The definition of spontaneous alternations was the entries into all arms on consecutive choices (i.e., $\mathrm{ABC}, \mathrm{BCA}$ or $\mathrm{CBA}$, but not $\mathrm{BAB})$. After each mouse was tested, the arms were cleaned by spraying them with $70 \%$ ethanol to remove smell and excreta. For each animal, the definition of alternation score (\%) was the actual numbers of alternations divided by the possible number (defined as the total numbers of arm entries minus two) multiplied by 100 , expressed by the following equation: $\%$ Alternation $=[$ (Numbers of alternations $) /($ Total arm entries -2$)] \times 100$. The total number of arm entries was indicated the locomotor activity. ${ }^{25)}$

Morris Water Maze Test (MWM) The maze is a round tank ( $45 \mathrm{~cm}$ in height and $90 \mathrm{~cm}$ in diameter) with four visual cues on the wall. The tank was set in a dusky (50 Lux), insulative room, and was artificially divided into 4 quadrants. A round black platform with a width of $6 \mathrm{~cm}$ and altitude of $29 \mathrm{~cm}$ was then set in the center of one quadrant of the tank. The tank was filled with water containing black dye $\left(24 \pm 1^{\circ} \mathrm{C}\right)$ to a depth of $30 \mathrm{~cm}$, such that the platform was not visible. The test was conducted over $8 \mathrm{~d}$, including 1 habituation day, 6 training days and 1 probe test day, as described elsewhere with slightly modifications. ${ }^{26)}$ On the habituation day, the mice were trained to swim for $60 \mathrm{~s}$ without a platform in the tank. During the 6 training days, the animals were trained to search for the hidden platform in the tank within $60 \mathrm{~s}$. When the animal stood on the platform, it was allowed to remain on it for $10 \mathrm{~s}$. If the animal could not find the platform within $60 \mathrm{~s}$, it was required to stand on the platform for $10 \mathrm{~s}$. Then, the mouse was put in its original cage and permitted to dry naturally after each trial. The mice had two training trials per day, and the time interval between the trials was $30 \mathrm{~min}$. The amount of time spent finding the platform (latency) in every trial was recorded. For each trial, the mouse was arbitrary put in the water facing a visual cue on the wall. On the probe test day, the animals were required to search for the platform for $60 \mathrm{~s}$, however, the platform had been removed from the tank. During the probe test, we recorded the swimming speed and the amount of swimming time in the target zone where the platform had originally been located through a video camera-installed Ethovision system (Noldus). During the 6 training days, the animals were administered bee pollen extract $(30,100$ or $300 \mathrm{mg} / \mathrm{kg}$, p.o.) or donepezil $(5 \mathrm{mg} / \mathrm{kg}$, p.o.) $1 \mathrm{~h}$ before the first training trial per day. The control group was given the equal volume of $10 \%$ Tween 80 solution rather than bee pollen extract or donepezil. In addition, the animals were also given scopolamine $(1 \mathrm{mg} / \mathrm{kg}$, i.p.) or $0.9 \%$ saline solution $30 \mathrm{~min}$ before the first training trial per day.
Western Blot Analysis (WB) Animals were sacrificed $1 \mathrm{~h}$ after a single treatment with bee pollen extract (100 or $300 \mathrm{mg} / \mathrm{kg}$, p.o.) or donepezil $(5 \mathrm{mg} / \mathrm{kg}$, p.o.), and brain tissues were isolated for WB. The vehicle group was given $10 \%$ Tween 80 solution rather than bee pollen extract or donepezil. Isolated whole hippocampi were separately homogenized using $200 \mu \mathrm{L}$ of ice-chilled Tris- $\mathrm{HCl}$ solution $(20 \mathrm{mM}, \mathrm{pH}$ 7.4), which contained $0.32 \mathrm{M}$ sucrose, $1 \mathrm{mM}$ ethylenediaminetetraacetic acid (EDTA), $1 \mathrm{mM}$ ethylene glycol bis(2-aminoethyl ether)- $N, N, N^{\prime}, N^{\prime}$-tetraacetic acid (EGTA), $1 \mathrm{mM}$ phenylmethylsulfonyl fluoride (PMSF), $1 \mathrm{mM}$ sodium orthovanadate and a protease inhibition tablet (Roche, Seoul, Korea) per $50 \mathrm{~mL}$ of solution. The homogenates were centrifuged twice at $15000 \times \boldsymbol{g}$ and $4^{\circ} \mathrm{C}$ for $20 \mathrm{~min}$. Then, the supernatant contained $15 \mu \mathrm{g}$ protein was loaded to sodium dodecyl sulfatepolyacrylamide gel electrophoresis (SDS-PAGE) (10\% gel) in a reducing condition. All proteins were transferred to polyvinylidene difluoride (PVDF) membranes using transfer solution [25 mM Tris- $\mathrm{HCl}$ ( $\mathrm{pH} 7.4$ ) including $192 \mathrm{mM}$ glycine and $20 \% \mathrm{v} / \mathrm{v}$ methanol] at $300 \mathrm{~mA}$ and $4^{\circ} \mathrm{C}$ for $2 \mathrm{~h}$. Then, using the $5 \%$ skim milk solution to block all membranes for $2 \mathrm{~h}$ at room temperature and using the primary antibodies to incubate them overnight at $4^{\circ} \mathrm{C}$. The primary antibodies including antiCREB or anti-pCREB (1:2000 dilution in 2\% skim milk); anti-ERK or anti-pERK (1:5000 dilution in 2\% skim milk); anti-Akt or anti-pAkt $(1: 3000$ dilution in $2 \%$ skim milk) and anti-GSK-3 $\beta$ or anti-pGSK-3 $\beta$ (1:3000 dilution in $2 \%$ skim milk). After incubation, all membranes were bathed with the Tris-buffered saline/Tween 20 (TBST) 6 times over $1 \mathrm{~h}$ and were incubated using secondary antibodies $(1: 3000)$ for $2 \mathrm{~h}$ at room temperature. Then, all membranes were washed using the TBST 6 times over $1 \mathrm{~h}$ again and were extended with enhanced chemiluminescence (AmershamLife Science, Arlington Heights, IL, U.S.A.). Immunoreactivity was imaged through the Multi-Gauge, bio-imaging program on an LAS-4000 mini (FUJIFILM Life Science USA, Stamford, CT, U.S.A.) and using the Multi Gauge version 3.2 software to analyze (FUJIFILM Holdings Corporation, Tokyo, Japan).

Previously, we reported that the increased level of BDNF at a specific time point is important for the facilitation of memory consolidation. ${ }^{27}$ Therefore, mice were sacrificed via cervical dislocation 3, 6, 9 and $12 \mathrm{~h}$ after a single treatment with bee pollen extract (100 or $300 \mathrm{mg} / \mathrm{kg}$, p.o.) or after the equal volume of $10 \%$ Tween 80 solution to investigate temporal changes in BDNF levels. The supernatant contained $15 \mu \mathrm{g}$ of protein was loaded to SDS-PAGE $(12 \%$ gel) in a reducing condition to determine the levels of BDNF. The primary antibodies were as follows: anti-BDNF (1:1000 dilution in $2 \%$ skim milk) and anti- $\beta$-actin $(1: 3000$ dilution in $2 \%$ skim milk). The other procedures were the same as described above.

RT-PCR Hippocampal total RNA was extracted by using Trizol reagent and $3 \mu \mathrm{g}$ of crude RNA was converted to cDNA according to the product information. The PCR amplification was conducted using an ABI StepOnePlus ${ }^{\mathrm{TM}}$ Real-Time PCR System (Applied Biosystems, Foster City, CA, U.S.A.) with SYBR Premix Ex Taq. The primers for BDNF (accession number AY057907, $T_{\mathrm{m}}=57.4^{\circ} \mathrm{C}$ ), tPA (accession number J03520, $T_{\mathrm{m}}=57.4^{\circ} \mathrm{C}$ ) and glyceraldehyde 3-phosphate dehydrogenase (GAPDH, accession number GU214026, $T_{\mathrm{m}}=56.4^{\circ} \mathrm{C}$ ) were used for PCR amplification, as follows: 
1. for BDNF, forward primer: 5'-GAC GACATC ACT GGC TGACA-3'; reverse primer: 5'-GCTGTGACCCAC TCG CTA AT-3'

2. for tPA, forward primer: 5'-CTC AGT GCC TGT CCGAAG TT-3'; reverse primer: 5'-CCAAGGTCT GGC ATC ACC AT-3'

3. for GAPDH, forward prime: 5'-CTA CCCCCAATG TGT CCG TC-3'; reverse primer: 5'-TGAAGTCGCAGGAGA CAACC-3'

The PCR product was normalized with that of GAPDH and analyzed relative gene expression data by using $2-\Delta \Delta C T$ Method. ${ }^{28)}$

Statistics All values are showed as the means \pm standard error of the mean (S.E.M.). Using the one-way ANOVA, ${ }^{6)}$ we analyzed the latencies of the PAT, the spontaneous alternations of the Y-M, the swimming time in target zone of the MWM and the data from the WB. The Student-NewmanKeuls test was used for multiple comparisons. The latencies in the training trial of the MWM, the expression levels of BDNF and the data from RT-PCR were analyzed by two-way ANOVA followed by a Bonferroni post hoc test, with day in the case of the MWM or time in the case of BDNF level as the first variable and treatment as the second variable. Statistical significance was set as $p<0.05$.

\section{RESULTS}

The Effects of Bee Pollen Extract on Memory Impairment Caused by Cholinergic Blockade or on Cognitive Enhancement in the PAT The PAT was conducted to assess the effects of bee pollen extract on memory impairment caused by scopolamine. As shown in Fig. 2A, there were no significant differences in the latencies among all the groups during the acquisition tentative $[F(5,59)=1.848, p>0.05]$, but significant group effects in the latencies were observed in the retention tentative $[F(5,56)=10.15, p<0.05]$. During
A

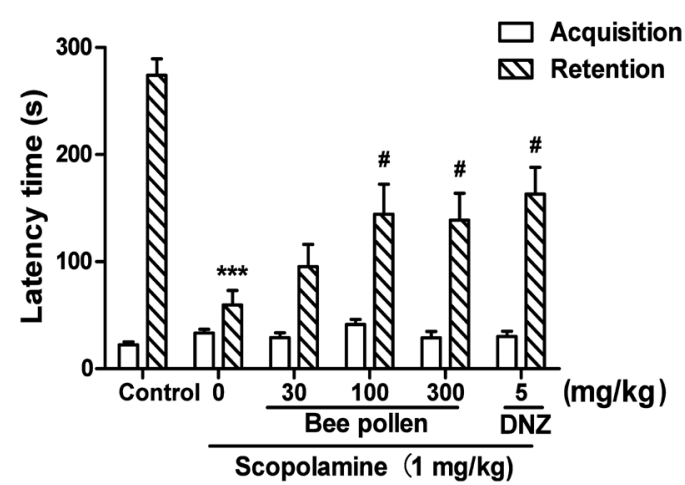

B

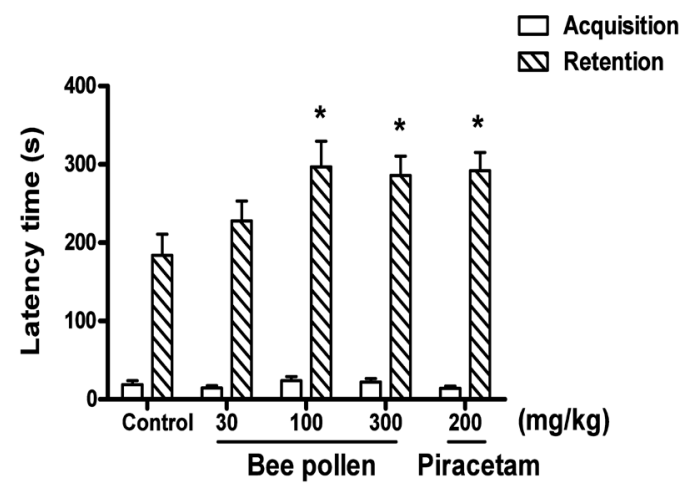

Fig. 2. The Effects of Bee Pollen on Memory Impairment Caused by Scopolamine (A) or on Cognitive Enhancement (B) in the PAT

In the case of the cognitively impaired mouse model, bee pollen extract ( $30,100 \mathrm{or} 300 \mathrm{mg} / \mathrm{kg}$, p.o.), donepezil (DNZ, $5 \mathrm{mg} / \mathrm{kg}$, p.o.) or the equal volume of vehicle solution ( $10 \%$ Tween 80 solution, p.o.) was given to the mice $1 \mathrm{~h}$ before the acquisition trial. Cognitive impairment was caused by scopolamine ( $1 \mathrm{mg} / \mathrm{kg}$, i.p.) $30 \mathrm{~min}$ before the acquisition trial. A retention tentative was carried out $24 \mathrm{~h}$ after the acquisition trial for $300 \mathrm{~s}$. In the case of the cognitive enhancement study, using a normal naïve mouse model, bee pollen extract $(30,100$ or $300 \mathrm{mg} / \mathrm{kg}$, p.o. $)$, piracetam $(200 \mathrm{mg} / \mathrm{kg}$, i.p.) or the equal volume of vehicle $(10 \%$ Tween 80 solution, p.o.) was given to the mice $1 \mathrm{~h}$ before the acquisition tentative. A retention tentative was carried out $24 \mathrm{~h}$ after the acquisition tentative for $600 \mathrm{~s}$. Data showed as means \pm S.E.M. $(n=8-10 /$ group) $\left(* * * p<0.001, * p<0.05\right.$, compared to the vehicle-administered control group; ${ }^{*} p<0.05$, compared to the scopolamine-administered group).

A

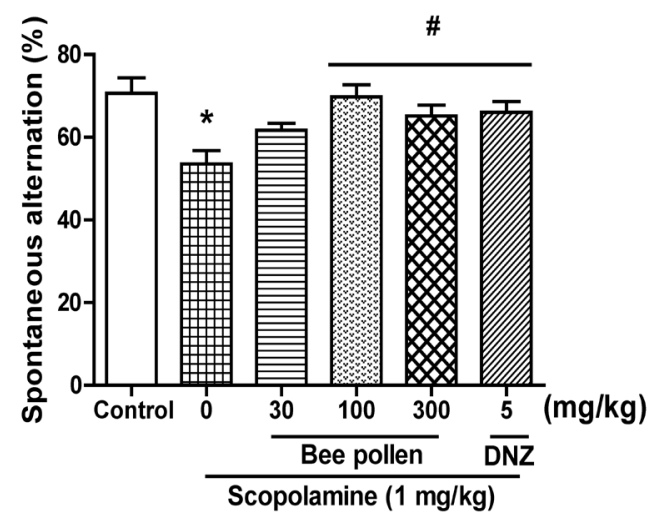

B

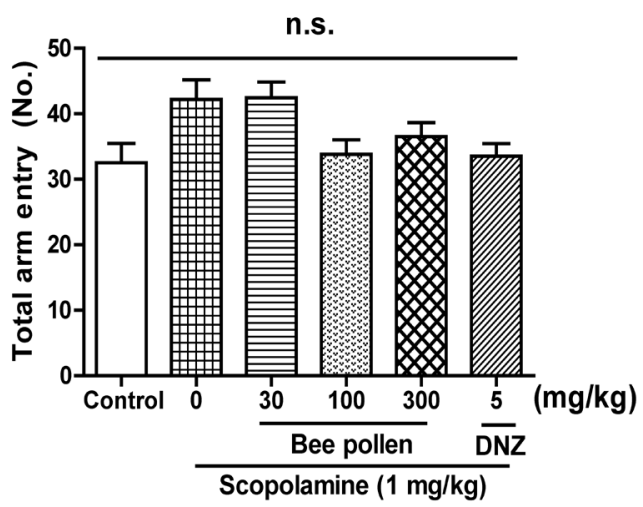

Fig. 3. The Effects of Bee Pollen on Scopolamine-Caused Memory Impairment in the Y-M

Bee pollen extract (30, 100 or $300 \mathrm{mg} / \mathrm{kg}$, p.o.), donepezil (DNZ, $5 \mathrm{mg} / \mathrm{kg}$, p.o.) or the equal volume of vehicle solution (10\% Tween 80 solution, p.o.) was given to the mice $1 \mathrm{~h}$ before the Y-M. Cognitive impairment was caused by scopolamine (1 mg/kg, i.p.) $30 \mathrm{~min}$ before the Y-M. Spontaneous alternation (A) and the number of arm entries (B) within an 8 -min period were recorded. Data showed as means \pm S.E.M. $(n=9-10 /$ group $)(* p<0.05$, compared to the vehicle-administered control group; ${ }^{\#} p<0.05$, compared to the scopolamine-administered group; n.s., not significant). 
the retention trial, the latency in the group given scopolamine $(1 \mathrm{mg} / \mathrm{kg}$, i.p.) was obviously shorter than that in the control group $(p<0.05)$. The reduced latency caused by scopolamine was obviously reversed by the bee pollen extract (100 or $300 \mathrm{mg} / \mathrm{kg}$, p.o.) or donepezil $(5 \mathrm{mg} / \mathrm{kg}$, p.o. $)(p<0.05)$.

Additionally, the PAT was also conducted to evaluate the effects of bee pollen on cognitive enhancement. As shown in Fig. 2B, there were no significant differences in the latencies among all the groups during the acquisition tentative $[F(4,49)=1.046, \quad p>0.05]$, but significant group effects in the latencies were observed in the retention tentative $[F(4,45)=3.296, p<0.05]$. The latencies of the bee pollen extract-administered groups (100 or $300 \mathrm{mg} / \mathrm{kg}$, p.o.) and of the piracetam-administered group $(200 \mathrm{mg} / \mathrm{kg}$, i.p.), as a positive control, were obviously increased compared to control group $(p<0.05)$.

The Effects of Bee Pollen Extract on ScopolamineCaused Memory Impairment in the Y-M The Y-M was conducted to evaluate the effects of bee pollen extract on the behavior of spontaneous alternation. As shown in Fig.
$3 \mathrm{~A}$, significant group effects were found in the spontaneous alternation $[F(5,56)=4.618, p<0.05]$. The percentage of spontaneous alternations in the group given scopolamine $(1 \mathrm{mg} / \mathrm{kg}$, i.p.) was obviously less than that of the group given vehicle solution $(p<0.05)$. The percentage of spontaneous alternations reduced by scopolamine was obviously reversed by the treatment with bee pollen extract $(100$ or $300 \mathrm{mg} / \mathrm{kg}$, p.o.) and of donepezil $(5 \mathrm{mg} / \mathrm{kg}$, p.o. $)(p<0.05)$. However, the total number of arm entries was not obviously different among all the groups $[F(5,58)=3.190, p>0.05]$ (Fig. 3B).

The Effects of Bee Pollen Extract on ScopolamineCaused Memory Impairment in the MWM The MWM was conducted to assess the effects of bee pollen extract on long-term and spatial memory. Two-way ANOVA indicated that there were significant group effects of the days $[F(5,320)=36.37, p<0.01]$ and treatments $[F(5,320)=19.16$, $p<0.01]$. As shown in Fig. 4A, the group given scopolamine $(1 \mathrm{mg} / \mathrm{kg}$, i.p.) exhibited longer escape latencies versus the control group from the second day to the last training day $(p<0.05)$. The escape latencies in response to the bee pollen

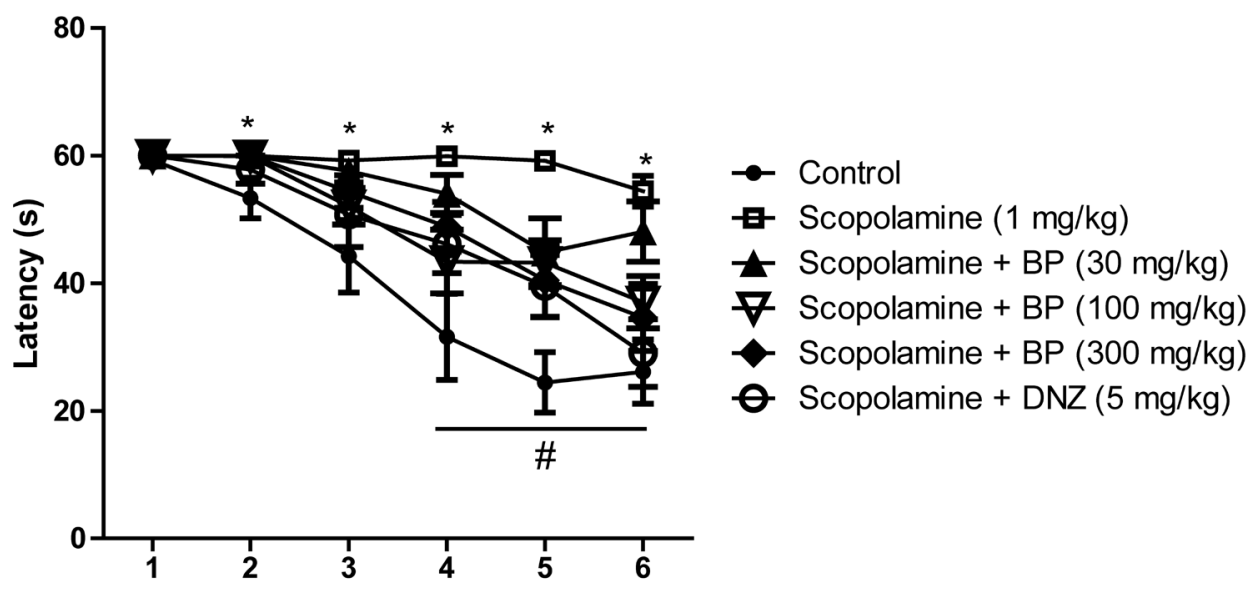

B

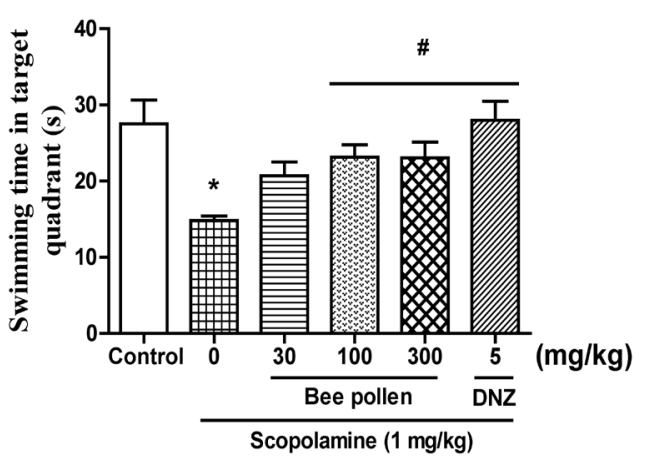

C

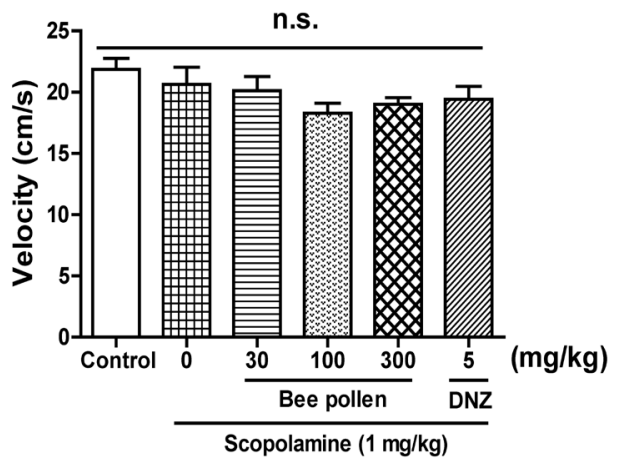

Fig. 4. The Effects of Bee Pollen on Scopolamine-Caused Memory Impairment in the MWM

Escape latencies during the training trial (A), swimming time in the target zone (B) and swimming velocity (C) during the probe test. Training trials were conducted for $6 \mathrm{~d}$. Bee pollen extract (BP, 30, 100 or $300 \mathrm{mg} / \mathrm{kg}$, p.o.), donepezil (DNZ, $5 \mathrm{mg} / \mathrm{kg}$, p.o.) or the equal volume of vehicle solution (10\% Tween 80 solution, p.o.) was given to the mice $1 \mathrm{~h}$ before the first training trial per day. Cognitive impairment was caused by scopolamine (1 mg/kg, i.p.) $30 \mathrm{~min}$ before the first training trial per day. The training trials and the probe test were conducted as described in the text. Data showed as means \pm S.E.M. $(n=8-10 /$ group $)(* p<0.05$, compared to the vehicle-administered control group; ${ }^{\sharp} p<0.05$, compared to the scopolamine-administered group; n.s., not significant). 


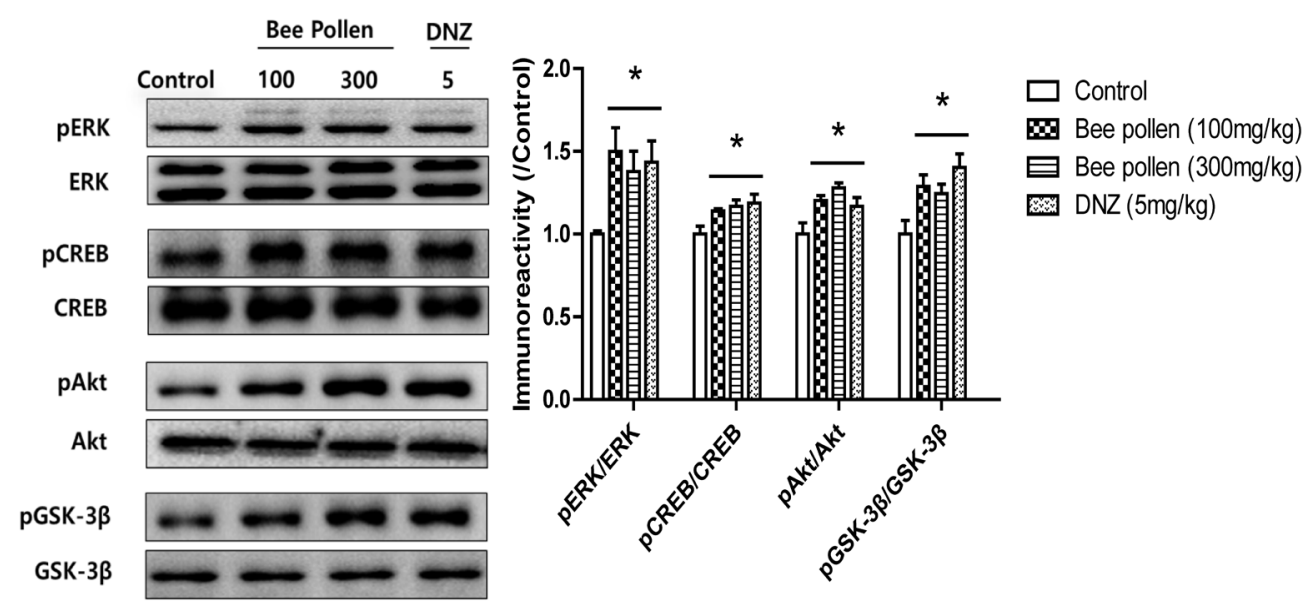

Fig. 5. The Effects of Bee Pollen on the Phosphorylation Levels of ERK, CREB, Akt and GSK-3 $\beta$ in the Hippocampus

The mice were sacrificed $1 \mathrm{~h}$ after the treatment with bee pollen extract (100 or $300 \mathrm{mg} / \mathrm{kg}$, p.o.), donepezil (DNZ, $5 \mathrm{mg} / \mathrm{kg}, p . o$.) or the equal volume of vehicle solution $(10 \%$ Tween 80 solution, p.o.). The immunoreactivity and quantitative analysis of pERK, pCREB, pAkt and pGSK-3 $\beta$ levels were measured in the hippocampi. Data showed as means \pm S.E.M. ( $n=4-5 /$ group) $(* p<0.05$, compared to the vehicle-administered control group).
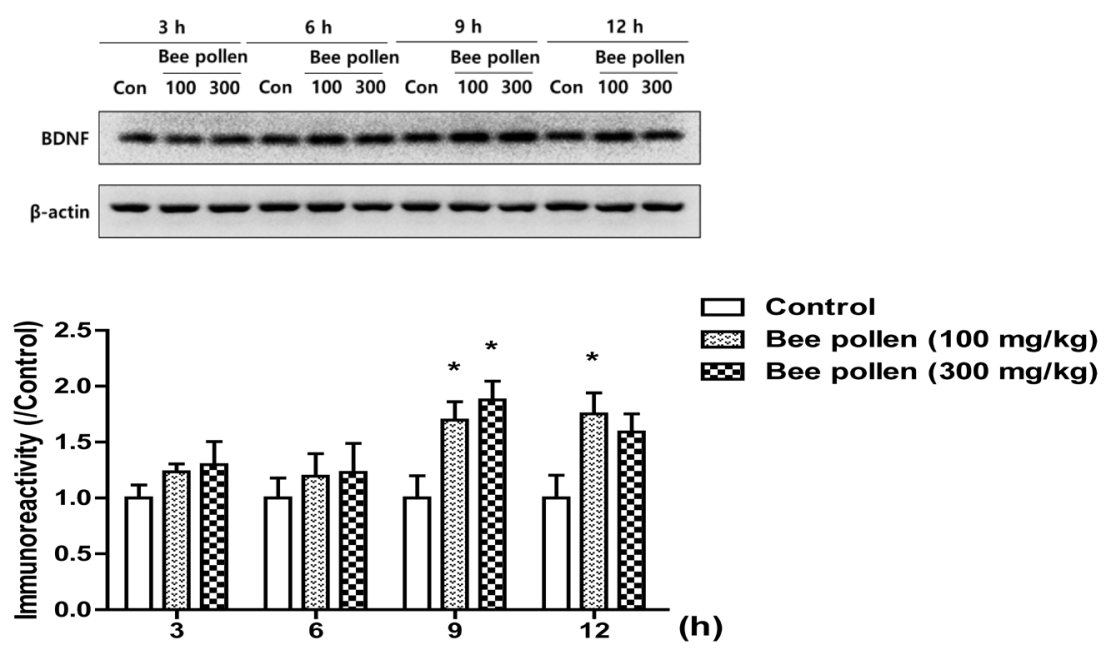

Fig. 6. The Temporal Changes in the BDNF Levels in the Hippocampus after the Treatment with Bee Pollen Extract

The mice were sacrificed 3, 6, 9 and $12 \mathrm{~h}$ after the treatment with bee pollen extract (100 or $300 \mathrm{mg} / \mathrm{kg}$, p.o.) or the equal volume of vehicle solution (Con, $10 \%$ Tween 80 solution, p.o.). The immunoreactivity and quantitative analysis of BDNF and $\beta$-actin levels were measured in the hippocampi. Data showed as means \pm S.E.M. $(n=4-5 /$ group) $\left({ }^{*} p<0.05\right.$, compared to the vehicle-administered control groups).

extract (100 or $300 \mathrm{mg} / \mathrm{kg}$, p.o.) and to donepezil $(5 \mathrm{mg} / \mathrm{kg}$, p.o.) were obviously shorter than those of the group given scopolamine on the fifth or sixth training days $(p<0.05)$. The swimming time in the target zone during probe trial (on day 7) was shown in Fig. 4B, and there were significant group effects in the swimming time $[F(5,56)=4.756, p<0.05]$. The swimming time in the target zone of the group given scopolamine was obviously shorter than that of the control group $(p<0.05)$. In addition, the reduced swimming time in the target zone caused by scopolamine was obviously reversed by bee pollen extract $(100$ or $300 \mathrm{mg} / \mathrm{kg}$, p.o.) and by donepezil $(5 \mathrm{mg} / \mathrm{kg}$, p.o. $)(p<0.05)$. However, as shown in Fig. $4 \mathrm{C}$, the swimming speeds among all groups were not significantly different $[F(5,56)=1.655, p>0.05]$.

The Effects of Bee Pollen Extract on the Phosphorylation Levels of ERK, CREB, Akt and GSK-3 $\beta$ and on the Expression Levels of BDNF in the Hippocampi WB was used to confirm which signaling molecule(s) is related to the effects of bee pollen extract on cognitive functions. As shown in Fig. 5, the phosphorylation levels of ERK
$[F(3,19)=3.798, p<0.05], \mathrm{CREB}[F(3,19)=4.254, p<0.05]$, Akt $[F(3,18)=5.668, p<0.05]$, or GSK-3 $\beta[F(3,18)=4.977$, $p<0.05]$ were significantly increased in the hippocampus in response to the administration of bee pollen extract (100 or $300 \mathrm{mg} / \mathrm{kg}$, p.o.) and to donepezil $(5 \mathrm{mg} / \mathrm{kg}$, p.o.) compared with the vehicle-administered control group. In addition, we also observed temporal changes in the expression levels of BDNF in the hippocampal tissue (Fig. 6). Two-way ANOVA indicated that there were significant group effects of time $[F(3,47)=3.35, p<0.05]$ and of the treatments $[F(2,47)=9.48, p<0.05]$. In contrast with the control groups, the expression levels of BDNF were significantly increased at 9 and $12 \mathrm{~h}$ after the treatment with bee pollen extract (100 or $300 \mathrm{mg} / \mathrm{kg}$, p.o. $)(p<0.05)$.

The Effects of Bee Pollen Extract on the mRNA Levels of BDNF and Tissue Plasminogen Activator (tPA) in the Hippocampi We examined the temporal profiles of BDNF mRNA expression levels after the bee pollen extract administration. We conducted RT-PCR to examine whether the bee pollen extract activates BDNF transcription in the 


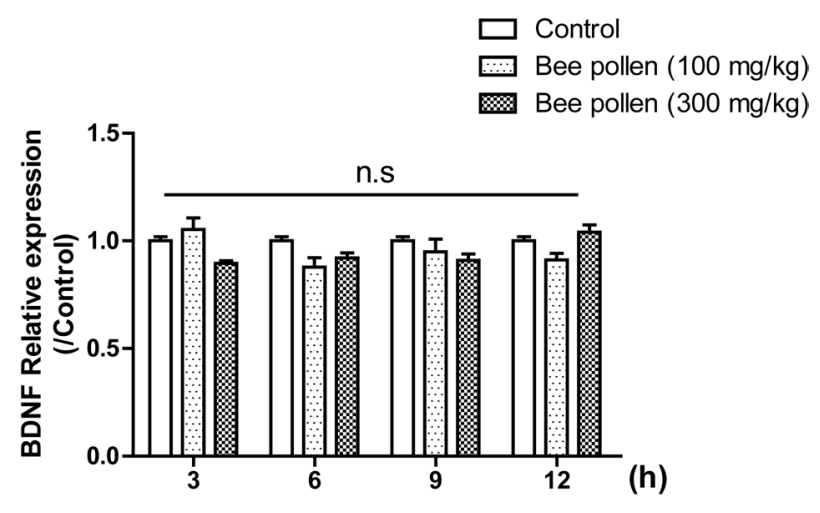

B

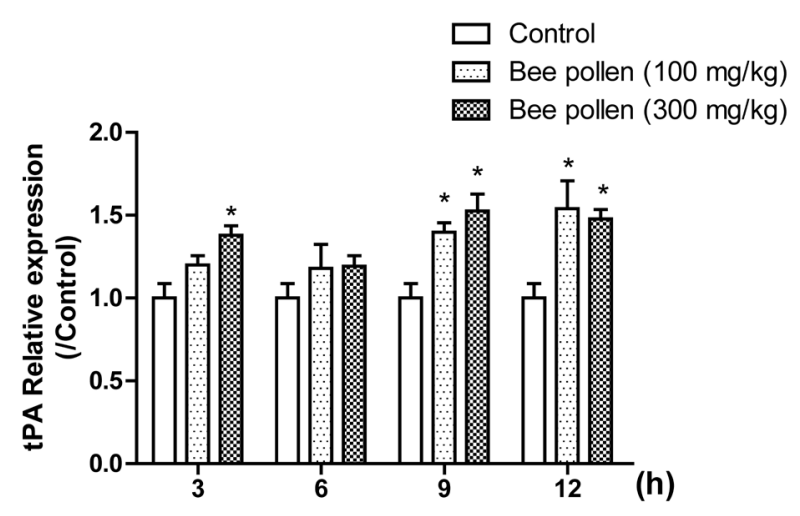

Fig. 7. The Temporal Profiles in the Levels of BDNF and tPA mRNA Expression in the Hippocampus after the Administration of Bee Pollen Extract

The levels of BDNF mRNA expression (A) and tPA mRNA expression (B) after the treatment with bee pollen extract were presented. The mice were sacrificed at $3,6,9$ and $12 \mathrm{~h}$ post-administration bee pollen extract $(100$ or $300 \mathrm{mg} / \mathrm{kg}$, p.o. $)$ or the same amount of vehicle solution (Con, $10 \%$ Tween 80 solution, p.o.). The levels of BDNF, tPA and Gapdh mRNA expression were measured in the hippocampi by RT-PCR. Data showed as means \pm S.E.M. ( $n=4-5 /$ group $)(* p<0.05$, compared to the vehicle-administered control groups).

hippocampus. Unfortunately, the levels of BDNF mRNA were not changed at 9 and $12 \mathrm{~h}$ after the administration of bee pollen extract [time, $F(3,53)=1.473, p>0.05$; treatment, $F(2,53)=3.254, p<0.05]$ (Fig. 7A). These results suggested that bee pollen extract did not affect the expression level of BDNF mRNA in the hippocampus. In the central nervous system (CNS), extracellular tPA elicits its proteolytic function by converting proBDNF into mature BDNF (mBDNF) which is essential for hippocampal memory consolidation. ${ }^{29,30)}$ Therefore, we determined the level of tPA mRNA expression level under the temporal bee pollen extract administration. Two-way ANOVA confirmed that there were significant group effects of time $[F(3,53)=3.509, p<0.05]$ and of the treatment $[F(2,53)=20.75, p<0.05]$. The levels of tPA mRNA expression were significantly increased at 9 and $12 \mathrm{~h}$ after the bee pollen extract administration (100 or $300 \mathrm{mg} / \mathrm{kg}$, p.o.) $(p<0.05)$ (Fig. 7B). These results indicated that bee pollen extract enhanced tPA expression level and it enhanced the conversion of proBDNF to mBDNF in the hippocampus, resulting in the increase of mBDNF levels at its 9 and $12 \mathrm{~h}$ post- administration 9 and $12 \mathrm{~h}$.

\section{DISCUSSION}

In this study, we found that bee pollen extract could ameliorate cholinergic blockade-induced cognitive impairment in mice. The administration of bee pollen extract significantly ameliorated cognitive impairment during the PAT, the Y-M and the MWM. In addition, bee pollen extract enhanced cognitive function in normal naïve mice in the passive avoidance test. Moreover, we also found that bee pollen extract could increase the phosphorylation levels of ERK, CREB, Akt and GSK- $3 \beta$ and the expression levels of BDNF in the hippocampus.

Bee pollen is known as a perfect food ingredient that exhibits free radical scavenging and antioxidant activities that could be used to ameliorate oxidative stress and neuroinflammation. ${ }^{31)}$ In addition, bee pollen has been reported to have therapeutic effects against glutamate excitotoxicity in an autistic rodent model. ${ }^{20)}$ If bee pollen has ameliorating effects against cognitive dysfunction caused by cholinergic blockade, it would be a promising option for the treatment of cognitive impairment because it could exert neuroprotective effects through the inhibition of excitotoxicity. In the present study, we observed that bee pollen extract significantly reversed the reduction in the latency caused by scopolamine during the retention trial measured of the PAT and lengthened the scopolamine-reduced swimming time in the target zone in the probe test of the MWM. Bee pollen extract also ameliorated spontaneous alternations versus the scopolamine-administered group in the Y-M. All these suggested that bee pollen extract could ameliorate cognitive impairment related to long-term or working memory.

Next, we investigated which enzyme or signaling molecule(s) is involved in the cognitive-ameliorating effects of bee pollen extract. Low levels of acetylcholine in brain tissue are one of the cause of cognitive dysfunction, ${ }^{32-34)}$ and, therefore, AChE inhibitors have been prescribed to enhance cholinergic function in AD therapy. Bee pollen extract exhibited similar behavioral consequences as those observed in the donepezil-treated group, suggesting that the ameliorating effects of bee pollen be probably related to increase the cholinergic neurotransmission system. Therefore, we conducted an AChE activity assay through an ex-vivo study to examine the effects of bee pollen extract on AChE activity. However, we did not find any significant changes after the treatment with bee pollen extract (data not shown). All these indicated that the cognitive-ameliorating effects of bee pollen might not be associated with the inhibition of AChE activity.

It is acknowledged that signaling pathways consisted of mitogen-activated protein kinase (MAPK) or Akt in the hippocampus play crucial roles in learning and memory processes. ERK, as a signaling molecule in the hippocampus, is associated with synaptic plasticity, ${ }^{35,36)}$ and its phosphorylation is required for long-term potentiation (LTP) ${ }^{37)}$ and for the consolidation of fear memory. ${ }^{38)} \mathrm{CREB}$, as a downstream signaling molecule of ERK, is also a well-known protein required for learning and memory processes. ${ }^{39)}$ CREB is not only important in neuronal plasticity, but also in spatial and long-term memory formation. ${ }^{40)}$ Thus, the ERK-CREB pathway plays an important role in learning and memory processes, and there- 
fore, we conducted Western blotting to determine whether bee pollen extract changes the phosphorylation levels of ERK or CREB. According to the results of the WB, the phosphorylation levels of ERK and CREB were obviously increased in the hippocampus in response to the administration of bee pollen extract. Another important molecule associated with learning and memory is Akt, which plays a role in LTP formation ${ }^{41)}$ and memory consolidation. ${ }^{42}$ GSK-3 $\beta$, a major substrate of $\mathrm{Akt}$, is known to be an important regulator of neurogenesis and synaptic plasticity in the hippocampus. ${ }^{43,44)}$ Suppression of the Akt-GSK-3 $\beta$ pathway could produce impairment of cognitive function or hyperphosphorylation of tau, which are both related to $\mathrm{AD}^{45,46)}$ In this study, we found that the treatment with bee pollen extract obviously increased the phosphorylation levels of Akt and GSK-3 $\beta$ in the hippocampi. Thus, the present results suggested that the cognitive-ameliorating effects of bee pollen could be derived from the activation of the ERK-CREB or the Akt-GSK-3 $\beta$ signaling pathway.

BDNF is an important molecule that is necessary for the consolidation of short-term memory to long-term memory and for synaptic plasticity in the hippocampus. ${ }^{47-49)}$ According to our results, the expression levels of BDNF were increased in response to the administration of bee pollen extract in the hippocampus. Therefore, the cognitive-ameliorating effects of bee pollen might be associated in part with the increase in BDNF expression levels. On the other hand, it has been reported that the expression levels of BDNF at specific time windows, 9 or $12 \mathrm{~h}$, are required for memory enhancement or consolidation. ${ }^{27,50,51)}$ We determined the temporal changes in BDNF levels, including 3, 6, 9 or $12 \mathrm{~h}$ after a single administration of bee pollen extract. The levels of BDNF significantly increased from 9 to $12 \mathrm{~h}$ after the administration of bee pollen extract. The levels of BDNF significantly increased from 9 to $12 \mathrm{~h}$ after the administration of bee pollen extract. However, bee pollen extract did not increase the level of mRNA of BDNF, suggesting that the conversion of proBDNF to mBDNF may be increased by BDNF processing enzymes. ${ }^{29,30)}$ BDNF processing is controlled by several converting enzymes such as pro-protein convertase 1 , furin, and matrix metalloproteinase-9, as well as tPA. ${ }^{52,53)}$ Therefore, we measured the mRNA level of tPA in the hippocampal tissue, and the increased mRNA level of tPA was observed. Thus, it is likely that the increase of BDNF level in the hippocampus might be derived from the increase of conversion rate of proBDNF to mBDNF. Previously, it has been reported that tPA transcription level is modulated by cAMP-responsive element bindings to the promotor region of tPA gene (PLAT; gene name of tPA). ${ }^{54-56}$ ) Therefore, our results suggest that bee pollen extract would increase tPA expression, probably, through ERK-CREB pathway, resulting in the enhancing conversion of proBDNF to mBDNF in the hippocampus. We also observed that the bee pollen extract enhanced cognitive function in normal naïve mice, as measured by the passive avoidance test. These results suggested that the administration of bee pollen extract could enhance cognitive function, in part, via the increase of mBDNF level.

Bee pollen contains many chemical and bioactive compounds, including amino acids, lipids, minerals, vitamins, flavonoids or phenolic acids. ${ }^{13)}$ Although we could not identify the active compound(s) contained in the bee pollen extract, we confirmed that bee pollen extract contains several flavonoid compounds, including quercetin, luteolin or apigenin. Most of these compounds are rich in many herbal materials, and are known to have ameliorating effects of cognitive function. ${ }^{57,58)}$ However, the amounts of them in bee pollen extract are low, ${ }^{13,14)}$ and we did not know the exact active compound(s) in bee pollen or their mechanisms of action. It is likely that bee pollen extract may exert its activities through the concerted effects of those bioactive compounds.

In summary, the above behavioral and biochemical results suggest that bee pollen could ameliorate scopolamine-induced cognitive impairment, including long-term and working memory dysfunctions, in part, by increasing the ERK-CREBBDNF or the Akt-GSK-3 $\beta$ signaling pathway. In addition, it could also enhance cognitive function by increasing the levels of BDNF expression. The present study suggested that bee pollen could be a potential therapeutic agent for the treatment of cognitive impairment caused by cholinergic dysfunction or for mild cognitive impairment.

Acknowledgments This research was supported by the High Value-added Food Technology Development Program (117077-03-1-HD040), Ministry for Food and Rural Affairs and Medical Research Center Program through the National Research Foundation of Korea (NRF) funded by the Ministry of Science and ICT (NRF-2017R1A5A2014768).

Conflict of Interest The authors declare no conflict of interest

\section{REFERENCES}

1) Helmes E, Bowler JV, Merskey H, Munoz DG, Hachinski VC. Rates of cognitive decline in Alzheimer's disease and dementia with Lewy bodies. Dement. Geriatr. Cogn. Disord., 15, 67-71 (2003)

2) Matthews FE, Brayne C, Lowe J, McKeith I, Wharton SB, Ince P. Epidemiological pathology of dementia: attributable-risks at death in the Medical Research Council Cognitive Function and Ageing Study. PLoS Med., 6, e1000180 (2009).

3) Foyet HS, Abaissou HH, Wado E, Acha EA, Alin C. Emilia coccinae (SIMS) G Extract improves memory impairment, cholinergic dysfunction, and oxidative stress damage in scopolamine-treated rats. BMC Complement. Altern. Med., 15, 333 (2015).

4) Weinstein JD. A unique and promising combination of medications for the treatment of Alzheimer's disease. Med. Hypotheses, 109, 53-55 (2017)

5) Candore G, Bulati M, Caruso C, Castiglia L, Colonna-Romano G, Di Bona D, Duro G, Lio D, Matranga D, Pellicano M, Rizzo C, Scapagnini G, Vasto S. Inflammation, cytokines, immune response, apolipoprotein E, cholesterol, and oxidative stress in Alzheimer disease: therapeutic implications. Rejuvenation Res., 13, 301-313 (2010)

6) Gulyaeva NV, Bobkova NV, Kolosova NG, Samokhin AN, Stepanichev MY, Stefanova NA. Molecular and cellular mechanisms of sporadic Alzheimer's disease: studies on rodent models in vivo. Biochemistry (Mosc.), 82, 1088-1102 (2017).

7) Cheignon C, Tomas M, Bonnefont-Rousselot D, Faller P, Hureau $\mathrm{C}$, Collin F. Oxidative stress and the amyloid beta peptide in Alzheimer's disease. Redox Biol., 14, 450-464 (2018).

8) Dias-Santagata D, Fulga TA, Duttaroy A, Feany MB. Oxidative stress mediates tau-induced neurodegeneration in Drosophila. J. Clin. Invest., 117, 236-245 (2007).

9) Owen RT. Memantine and donepezil: a fixed drug combination for 
the treatment of moderate to severe Alzheimer's dementia. Drugs Today (Barc.), 52, 239-248 (2016).

10) Terry AV Jr, Buccafusco JJ. The cholinergic hypothesis of age and Alzheimer's disease-related cognitive deficits: recent challenges and their implications for novel drug development. J. Pharmacol. Exp. Ther., 306, 821-827 (2003).

11) Doody RS. Refining treatment guidelines in Alzheimer's disease. Geriatrics, (Suppl.), 2005, 14-20 (2005).

12) Farlow M, Veloso F, Moline M, Yardley J, Brand-Schieber E, Bibbiani F, Zou H, Hsu T, Satlin A. Safety and tolerability of donepezil $23 \mathrm{mg}$ in moderate to severe Alzheimer's disease. BMC Neurol., 11, 57 (2011)

13) Komosinska-Vassev K, Olczyk P, Kazmierczak J, Mencner L, Olczyk K. Bee pollen: chemical composition and therapeutic application. Evid. Based Complement. Alternat. Med., 2015, 297425 (2015).

14) Denisow B, Denisow-Pietrzyk M. Biological and therapeutic properties of bee pollen: a review. J. Sci. Food Agric., 96, 4303-4309 (2016).

15) Silva TM, Camara CA, Lins AC, Agra Mde F, Silva EM, Reis IT, Freitas BM. Chemical composition, botanical evaluation and screening of radical scavenging activity of collected pollen by the stingless bees Melipona rufiventris (Uruçu-amarela). An. Acad. Bras. Cienc., 81, 173-178 (2009).

16) Sun L, Guo Y, Zhang Y, Zhuang Y. Antioxidant and anti-tyrosinase activities of phenolic extracts from rape bee pollen and inhibitory melanogenesis by cAMP/MITF/TYR pathway in B16 mouse melanoma cells. Front Pharmacol., 8, 104 (2017).

17) Pascoal A, Rodrigues S, Teixeira A, Feas X, Estevinho LM. Biological activities of commercial bee pollens: antimicrobial, antimutagenic, antioxidant and anti-inflammatory. Food Chem. Toxicol., 63, 233-239 (2014)

18) Fatrcová-Sramková K, Nôžková J, Kačániová M, Máriássyová M, Rovná K, Stričík M. Antioxidant and antimicrobial properties of monofloral bee pollen. J. Environ. Sci. Health B, 48, 133-138 (2013).

19) Cornara L, Biagi M, Xiao J, Burlando B. Therapeutic properties of bioactive compounds from different honeybee products. Front Pharmacol., 8, 412 (2017).

20) El-Ansary A, Al-Salem HS, Asma A, Al-Dbass A. Glutamate excitotoxicity induced by orally administered propionic acid, a short chain fatty acid can be ameliorated by bee pollen. Lipids Health Dis., 16, 96 (2017).

21) Myśliwiec Z. Effect of pollen extracts (cernitin preparation) on selected biochemical parameters of liver in the course of chronic ammonium fluoride poisoning in rats. Ann. Acad. Med. Stetin., 39, 71-85 (1993).

22) Park SJ, Kim DH, Jung JM, Kim JM, Cai M, Liu X, Hong JG, Lee $\mathrm{CH}$, Lee KR, Ryu JH. The ameliorating effects of stigmasterol on scopolamine-induced memory impairments in mice. Eur. J. Pharmacol., 676, 64-70 (2012).

23) Kim E, Ko HJ, Jeon SJ, Lee S, Lee HE, Kim HN, Woo ER, Ryu JH. The memory-enhancing effect of erucic acid on scopolamineinduced cognitive impairment in mice. Pharmacol. Biochem. Behav., 142, 85-90 (2016).

24) Lee S, Park HJ, Jeon SJ, Kim E, Lee HE, Kim H, Kwon Y, Zhang J, Jung IH, Ryu JH. Cognitive ameliorating effect of Acanthopanax koreanum against scopolamine-induced memory impairment in mice. Phytotherapy Research, 31, 425-432 (2017).

25) Sarter M, Bodewitz G, Stephens DN. Attenuation of scopolamineinduced impairment of spontaneous alteration behaviour by antagonist but not inverse agonist and agonist beta-carbolines. Psychopharmacology (Berl.), 94, 491-495 (1988)

26) Jung WY, Kim H, Jeon SJ, Park HJ, Choi HJ, Kim NJ, Kim DH, Jang DS, Ryu JH. Eclalbasaponin II ameliorates the cognitive impairment induced by cholinergic blockade in mice. Neurochem. Res., 43, 351-362 (2018).
27) Kim DH, Kim JM, Park SJ, Cai M, Liu X, Lee S, Shin CY, Ryu JH. GABA(A) receptor blockade enhances memory consolidation by increasing hippocampal BDNF levels. Neuropsychopharmacology, 37, 422-433 (2012).

28) Livak KJ, Schmittgen TD. Analysis of relative gene expression data using real-time quantitative PCR and the $2^{-\Delta \Delta \mathrm{CT}_{\mathrm{T}}}$ method. Methods, 25, 402-408 (2001).

29) Obiang P, Maubert E, Bardou I, Nicole O, Launay S, Bezin L, Vivien $\mathrm{D}$, Agin V. Enriched housing reverses age-associated impairment of cognitive functions and tPA-dependent maturation of BDNF. Neurobiol. Learn. Mem., 96, 121-129 (2011).

30) Pang PT, Teng HK, Zaitsev E, Woo NT, Sakata K, Zhen S, Teng KK, Yung WH, Hempstead BL, Lu B. Cleavage of proBDNF by tPA/plasmin is essential for long-term hippocampal plasticity. Science, 306, 487-491 (2004).

31) Al-Salem HS, Bhat RS, Al-Ayadhi L, El-Ansary A. Therapeutic potency of bee pollen against biochemical autistic features induced through acute and sub-acute neurotoxicity of orally administered propionic acid. BMC Complement. Altern. Med., 16, 120 (2016).

32) Bartus RT, Dean RL 3rd, Beer B, Lippa AS. The cholinergic hypothesis of geriatric memory dysfunction. Science, 217, 408-414 (1982)

33) Birthelmer A, Lazaris A, Schweizer T, Jackisch R, Cassel JC. Presynaptic regulation of neurotransmitter release in the cortex of aged rats with differential memory impairments. Pharmacol. Biochem. Behav., 75, 147-162 (2003)

34) Auld DS, Kornecook TJ, Bastianetto S, Quirion R. Alzheimer's disease and the basal forebrain cholinergic system: relations to betaamyloid peptides, cognition, and treatment strategies. Prog. Neurobiol., 68, 209-245 (2002).

35) Adams JP, Sweatt JD. Molecular psychology: roles for the ERK MAP kinase cascade in memory. Annu. Rev. Pharmacol. Toxicol., 42, 135-163 (2002).

36) Abdul Rahman NZ, Greenwood SM, Brett RR, Tossell K, Ungless MA, Plevin R, Bushell TJ. Mitogen-activated protein kinase phosphatase-2 deletion impairs synaptic plasticity and hippocampaldependent memory. J. Neurosci., 36, 2348-2354 (2016).

37) Petrovic MM, Viana da Silva S, Clement JP, Vyklicky L, Mulle C, Gonzalez-Gonzalez IM, Henley JM. Metabotropic action of postsynaptic kainate receptors triggers hippocampal long-term potentiation. Nat. Neurosci., 20, 529-539 (2017).

38) Trifilieff P, Herry C, Vanhoutte P, Caboche J, Desmedt A, Riedel G, Mons N, Micheau J. Foreground contextual fear memory consolidation requires two independent phases of hippocampal ERK/CREB activation. Learn. Mem., 13, 349-358 (2006).

39) Sakamoto K, Karelina K, Obrietan K. CREB: a multifaceted regulator of neuronal plasticity and protection. J. Neurochem., 116, 1-9 (2011).

40) Ji ST, Kim MS, Park HR, Lee E, Lee Y, Jang YJ, Kim HS, Lee J. Diallyl disulfide impairs hippocampal neurogenesis in the young adult brain. Toxicol. Lett., 221, 31-38 (2013).

41) Jope RS, Yuskaitis CJ, Beurel E. Glycogen synthase kinase-3 (GSK3): inflammation, diseases, and therapeutics. Neurochem. Res., 32, 577-595 (2007)

42) Levenga J, Wong H, Milstead RA, Keller BN, LaPlante LE, Hoeffer CA. AKT isoforms have distinct hippocampal expression and roles in synaptic plasticity. eLife, 6, e30640 (2017).

43) Shahab L, Plattner F, Irvine EE, Cummings DM, Edwards FA. Dynamic range of GSK $3 \alpha$ not GSK $3 \beta$ is essential for bidirectional synaptic plasticity at hippocampal CA3-CA1 synapses. Hippocampus, 24, 1413-1416 (2014).

44) Zhang H, Yang X, Qin X, Niu Q. Caspase-3 is involved in aluminum-induced impairment of long-term potentiation in rats through the Akt/GSK-3 $\beta$ pathway. Neurotox. Res., 29, 484-494 (2016).

45) Xian YF, Mao QQ, Wu JC, Su ZR, Chen JN, Lai XP, Ip SP, Lin ZX. Isorhynchophylline treatment improves the amyloid- $\beta$-induced 
cognitive impairment in rats via inhibition of neuronal apoptosis and tau protein hyperphosphorylation. J. Alzheimer's Dis., 39, 331-346 (2014).

46) Li H, Kang T, Qi B, Kong L, Jiao Y, Cao Y, Zhang J, Yang J. Neuroprotective effects of ginseng protein on PI3K/Akt signaling pathway in the hippocampus of D-galactose $/ \mathrm{AlCl}_{3}$ inducing rats model of Alzheimer's disease. J. Ethnopharmacol., 179, 162-169 (2016).

47) Kang H, Welcher AA, Shelton D, Schuman EM. Neurotrophins and time: different roles for TrkB signaling in hippocampal long-term potentiation. Neuron, 19, 653-664 (1997).

48) Tyler WJ, Alonso M, Bramham CR, Pozzo-Miller LD. From acquisition to consolidation: on the role of brain-derived neurotrophic factor signaling in hippocampal-dependent learning. Learn. Mem., 9, 224-237 (2002)

49) Ko YH, Kwon SH, Lee SY, Jang CG. Liquiritigenin ameliorates memory and cognitive impairment through cholinergic and BDNF pathways in the mouse hippocampus. Arch. Pharm. Res., 40, 12091217 (2017)

50) Kim DH, Lee Y, Lee HE, Park SJ, Jeon SJ, Jeon SJ, Cheong JH, Shin CY, Son KH, Ryu JH. Oroxylin A enhances memory consolidation through the brain-derived neurotrophic factor in mice. Brain Res. Bull., 108, 67-73 (2014).

51) Bekinschtein P, Cammarota M, Igaz LM, Bevilaqua LR, Izquierdo I, Medina JH. Persistence of long-term memory storage requires a late protein synthesis- and BDNF-dependent phase in the hippocampus. Neuron, 53, 261-277 (2007).

52) Leßmann V, Brigadski T. Mechanisms, locations, and kinetics of synaptic BDNF secretion: an update. Neurosci. Res., 65, 11-22 (2009).
53) Mizoguchi H, Nakade J, Tachibana M, Ibi D, Someya E, Koike H, Kamei H, Nabeshima T, Itohara S, Takuma K, Sawada M, Sato J, Yamada K. Matrix metalloproteinase-9 contributes to kindled seizure development in pentylenetetrazole-treated mice by converting pro-BDNF to mature BDNF in the hippocampus. J. Neurosci., 31, 12963-12971 (2011).

54) Dunoyer-Geindre S, Rivier-Cordey AS, Caetano C, Fish RJ, Kruithof EK. Effect of regulatory element DNA methylation on tissue-type plasminogen activator gene expression. PLOS ONE, 11, e0167588 (2016).

55) Medcalf RL, Ruegg M, Schleuning WD. A DNA motif related to the cAMP-responsive element and an exon-located activator protein-2 binding site in the human tissue-type plasminogen activator gene promoter cooperate in basal expression and convey activation by phorbol ester and cAMP. J. Biol. Chem., 265, 14618-14626 (1990).

56) Sheikh AM, Ochi H, Masuda J. Lysophosphatidylcholine induces tPA gene expression through CRE-dependent mechanism. Biochem. Biophys. Res. Commun., 329, 71-77 (2005).

57) Vauzour D. Effect of flavonoids on learning, memory and neurocognitive performance: relevance and potential implications for Alzheimer's disease pathophysiology. J. Sci. Food Agric., 94, 1042-1056 (2014)

58) Arsalandeh F, Ahmadian S, Foolad F, Khodagholi F, Farimani MM, Shaerzadeh F. Beneficial effect of flavone derivatives on A $\beta$ induced memory deficit is mediated by peroxisome proliferator-activated receptor $\gamma$ coactivator $1 \alpha$ : a comparative study. Int. J. Toxicol., 34, 274-283 (2015). 